\title{
Production of toxic pavettamine and pavettamine conjugates in the gousiekte-causing Fadogia homblei plant and its relation to the bacterial endosymbiont
}

Daan Van Elst ${ }^{\mathrm{a} *}$, Braam van $\mathrm{Wyk}^{\mathrm{b}}$, Anitra Schultz ${ }^{\mathrm{c}}$ and Els Prinsen ${ }^{\mathrm{a}}$

${ }^{a}$ University of Antwerp, Plant Growth and Development, Biology Dept., Groenenborgerlaan 171, 2020, Antwerpen, Belgium.

${ }^{\mathrm{b}}$ H.G.W.J. Schweickerdt Herbarium, University of Pretoria, Pretoria 0002, South Africa

${ }^{c}$ Agriculture Research Council-Onderstepoort Veterinary Institute, Section of Toxicology, Onderstepoort 0110, South Africa.

*corresponding author

Daan.VanElst@ua.ac.be

Tel. +3232653714 ,

Fax. +3232653417

Braam.VanWyk@up.ac.za

SchultzA@arc.agric.za

Els.Prinsen@ua.ac.be

\begin{abstract}
Plant poisoning of livestock is responsible for considerable economic losses in southern Africa. Six plant species of the Rubiaceae family are known to cause gousiekte, a cardiac syndrome of ruminants induced by ingestion of the toxic compound pavettamine. Progress in understanding the aetiology of this disease is largely hampered by the variable toxicity of the plants and the
\end{abstract}


absence of a quantification method for pavettamine. The pavettamine concentration in leaf samples of Fadogia homblei, a known gousiekte causing plant, was analyzed by massspectrometry. In the most apical leaf pair, the highest concentration of pavettamine was detected. Distal leaves contained progressively less pavettamine. Besides a significant amount of free pavettamine, most pavettamine was found to occur in a conjugated form. To which molecules the pavettamine is conjugated remains unknown as is the function of conjugated pavettamine in the development of gousiekte. All know gousiekte-causing plants contain symbiotic bacteria in their leaves; it was hypothesized that these bacteria might be involved in the production of pavettamine. However, analysis of in vitro cultures of the Fadogia homblei endosymbiont revealed no production of pavettamine. Pavettamine is therefore not produced by the bacteria alone. It is either the product of the interaction with the plant or solely produced by the host.

\section{Keywords}

Fadogia homblei, Rubiaceae, Burkholderia, Endosymbiont, Mass-spectrometry, Pavettamine, Gousiekte

\footnotetext{
Abbreviations

Dap, diaminopropane ; Put, putrescine; Cad, cadaverine; Spd, spermidine ; Spm, spermine; Agm, agmatine; Dah, diaminoheptane; Pav, Pavettamine; CFU, Colony Forming Units; DPD, 2,2-Dipyridyl; MES, 2-( $N$-morpholino)ethanesulfonic acid; MOPS, $3-(N$ morpholino)propanesulfonic acid
} 


\section{Introduction}

Gousiekte (Afrikaans for "quick disease") is a disease of ruminants caused by the ingestion of certain poisonous plants. It is rated one of the six most important plant toxicoses in southern Africa. The disease is characterized by acute heart failure, usually without premonitory signs, five to eight weeks after the initial intake of toxic plants. To date six species spread over three genera of the Rubiaceae family have been identified as the causative agents: Vangueria (syn. Pachystigma) pygmaeum, V. thamnus, V. latifolium, Pavetta harborii, P. schumanniana and Fadogia homblei (Kellerman et al., 2005; Theiler et al., 1923; Pretorius and Terblanche, 1967; Hurter et al., 1972). The toxic principle of the plants was isolated in 1995 (Fourie et al., 1995) and its chemical structure was published in 2010 (Bode et al., 2010). The active compound is a polyamine and was named pavettamine.

Polyamines are low molecular weight compounds, which are positively charged at a physiological $\mathrm{pH}$. They can therefore bind to negatively charged molecules such as nucleic acids, phospholipids or proteins. Polyamines play important roles in several developmental processes, such as root growth, somatic embryogenesis, development of flowers and fruits, plant response to biotic and abiotic stress, and are thus required for normal growth of plants (Walters, 2003; Kusano et al., 2008). Polyamines are found in every plant cell either in a free form or bound to phenolic acids, other low molecular weight compounds or to macromolecules (Bassard et al., 2010; Galston and Sahwney, 1990). Pavettamine is the only naturally occurring polyamine to be incriminated in the poisoning of livestock (Schultz et al., 2001). However, the function of pavettamine in the physiology of the plant is unknown and it has to be elucidated whether the compound occurs in a conjugated form in plant tissues. 
All gousiekte-causing plants contain bacterial endosymbionts in their leaves. Both gousiektecausing Pavetta species harbour endophytic bacteria in distinct nodules within the mesophyll of the leaf, visible as raised, often dark green bumps on the lamina surface. Van Wyk et al. (1990) showed the presence of non-nodulating endophytic bacteria in the leaves of Fadogia homblei and the three Vangueria species. In these plants, the bacteria are associated with masses of mucilage found in the intercellular spaces between the leaf mesophyll cells. Recent genomic analysis of the bacterial endosymbionts in members of the Rubiaceae revealed that all plant species causing gousiekte, contain endophytic bacteria that belong to the genus Burkholderia (Lemaire et al., 2011; Verstraete et al., 2011). Twenty-four other Rubiaceae plants that are not implicated in the disease but that grow in the same area as the gousiekteinducing plants were found devoid of endosymbiotic bacteria (Verstraete et al., 2011). Animal feeding studies confirmed that two of these non-bacteriophilous Rubiaceae species were unable to cause gousiekte (Hurter et al., 1972; Theiler et al., 1923; Verstraete et al., 2011). These observations lead to the hypothesis that the bacterial endosymbionts might be involved in the aetiology of gousiekte. At present it is, however, not known whether the endosymbiont of the plants plays any role in the production of the poisonous compound. In bacteria, various functions have been attributed to polyamines, thus confirming the physiological importance of these molecules. They are for instance components of the outer membrane in gram-negative bacteria, and they are involved in the biosynthesis of siderophores, acid resistance and biofilm formation (Kusano et al., 2008; Wortham et al., 2007). 
In the present study we focus on the gousiekte-causing plant Fadogia homblei ('wild date') and its bacterial endosymbiont, which can be cultured outside its host. The bacterial isolates show high similarity to Burkholderia caledonica and appear to be host-specific at the population level (Verstraete et al., 2011). Fadogia homblei De Wild. (=F. monticola Robyns) is a perennial, dwarf shrublet with a deep root system and clonal growth (geofrutex; also referred to as a geoxylic suffrutex). The aerial parts of the plant usually are deciduous during winter, but in spring (approximately September to October) clusters of fresh stems sprout from the perennial underground rootstocks, rendering the plants easily accessible to grazers. It is a common species in grassland and savannah, with a distribution extending from Pretoria in South Africa eastwards to Swaziland and northwards to the Limpopo Province and into Zimbabwe, Zambia and Mozambique (Hurter et al., 1972).

Until now many problems regarding the inconsistent toxicity of the gousiekte-causing plants have hindered studies that aimed at a better understanding of the disease. Basic knowledge on the plant physiological aspects of pavettamine is lacking. The absence of a quantification method for pavettamine further increases the impediment on progress into understanding gousiekte. Therefore, we created a selective, fast and sensitive method to measure pavettamine along with other more common polyamines through detection with tandem mass spectrometry (MS-MS) after derivatization with benzoyl chloride and separation by ultra performance liquid chromatography (UPLC $\left.{ }^{\mathrm{TM}}\right)$. The five most apical leaf pairs of Fadogia homblei plants were analyzed for pavettamine and eventual pavettamine conjugates. Also the Fadogia homblei endosymbiont was subjected to this analysis, providing new insights into the origin of the toxin. 


\section{Results and Discussion}

The gousiekte plant Fadogia homblei contains pavettamine in its leaves

Table 1: Free polyamine concentration in distal leaf pairs of Fadogia homblei (nmol/g dry wt \pm s.d.)

\begin{tabular}{|l|c|c|c|c|c|}
\hline & Putrescine & Cadaverine & Spermidine & Spermine & Pavettamine \\
\hline & & & & & \\
\hline $1^{\text {st }}$ leaf pair & $492 \pm 13$ & $26 \pm 0.7$ & $229 \pm 7$ & $148 \pm 6$ & $296 \pm 47$ \\
\hline $2^{\text {nd }}$ leaf pair & $556 \pm 20$ & $31 \pm 1.4$ & $192 \pm 9$ & $122 \pm 6$ & $218 \pm 19$ \\
\hline $3^{\text {rd }}$ leaf pair & $516 \pm 22$ & $38 \pm 0.9$ & $166 \pm 3$ & $117 \pm 3$ & $154 \pm 20$ \\
\hline $4^{\text {th }}$ leaf pair & $432 \pm 20$ & $37 \pm 1.6$ & $175 \pm 4$ & $120 \pm 3$ & $102 \pm 11$ \\
\hline $5^{\text {th }}$ leaf pair & $447 \pm 23$ & $38 \pm 1.6$ & $153 \pm 11$ & $104 \pm 9$ & $82 \pm 6$ \\
\hline
\end{tabular}

Polyamine levels in the first five leaf pairs of Fadogia homblei plants (analyzed together with their bacterial endosymbiont) were determined with the mass spectrometry method described below. Mean free and acid soluble conjugated polyamine concentrations are summarized in Table 1 and 2, respectively. The most abundant free amine is the diamine putrescine, followed by (depending on the leaf pair) the triamines spermidine and pavettamine and the tetra-amine spermine. Small amounts of unconjugated diaminopropane (concentrations between 1.12-1.33 $\mathrm{nmol} / \mathrm{mg}$ dry wt) and agmatine were also found in the leaves $(0.4-1 \mathrm{nmol} / \mathrm{mg}$ dry wt). Differences in polyamine content between the leaf pairs were analyzed using ANOVA followed by Tukey's multiple comparisons test (Fig. 1). Polyamines are generally abundant in 

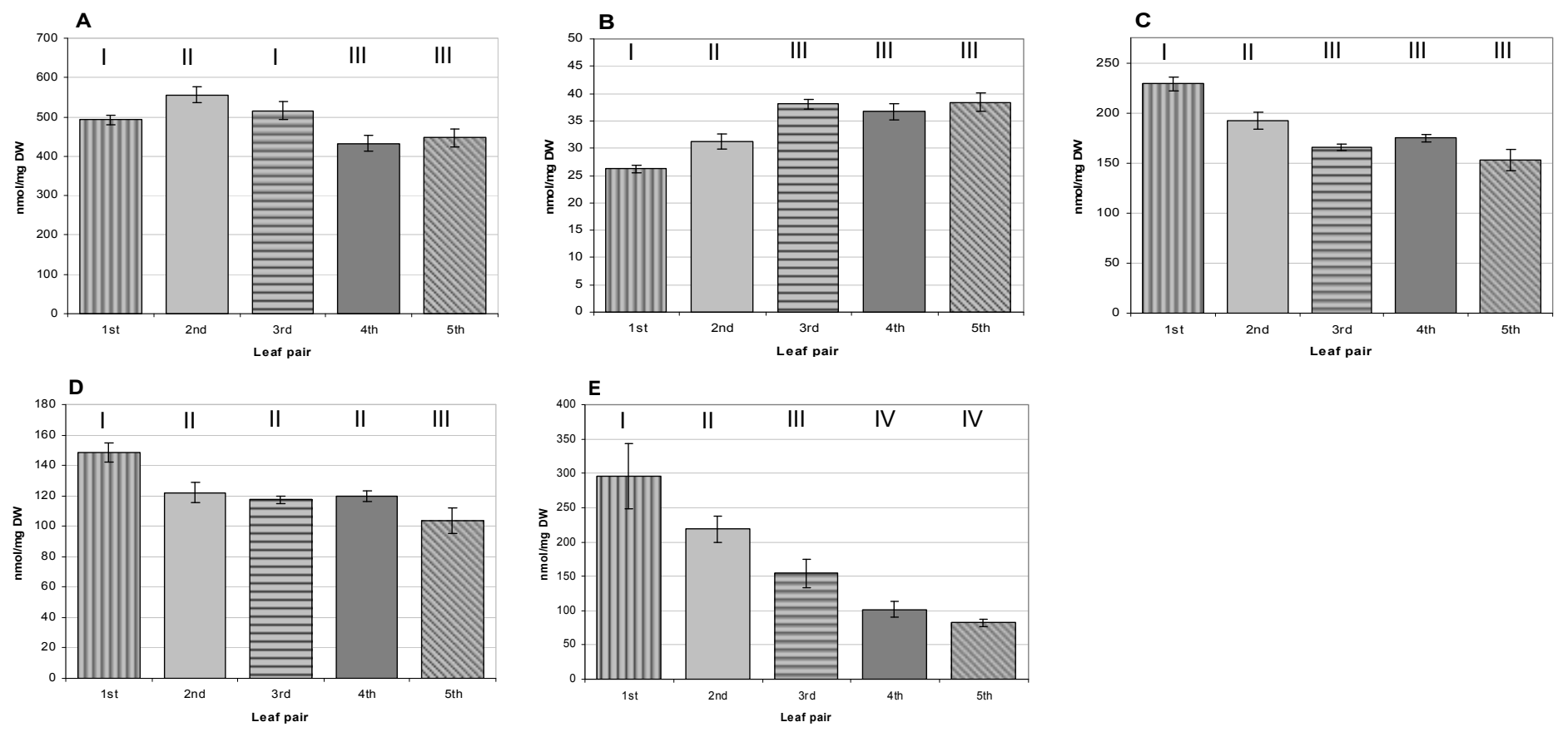

Fig. 1. Levels of free polyamines analysed in different distal leaf pairs of Fadogia homblei. A: putrescine, B: cadaverine, C: spermidine, D: spermine, E: pavettamine. Means \pm s.d. $(\mathrm{N}=5)$. Means with the same Roman numeral are not significantly different. 
young, non-senescent organs, and decline to a lower concentration as organs age and senesce (Galston and Sahwney, 1990). Our analysis shows a similar tendency for spermidine, spermine

Table 2: Conjugated polyamine concentration in distal leaf pairs of Fadogia homblei (nmol/g dry wt \pm s.d.)

\begin{tabular}{|l|c|c|c|c|c|}
\hline & Putrescine & Cadaverine & Spermidine & Spermine & Pavettamine \\
\hline & & & & & \\
\hline $1^{\text {st }}$ leaf pair & $700 \pm 115$ & $21.4 \pm 4.1$ & $239 \pm 31$ & $\mathrm{ND}^{\mathrm{a}}$ & $3191 \pm 462$ \\
\hline $2^{\text {nd }}$ leaf pair & $781 \pm 79$ & $31.2 \pm 6.7$ & $222 \pm 17$ & $\mathrm{ND}^{\mathrm{a}}$ & $2097 \pm 527$ \\
\hline $3^{\text {rd }}$ leaf pair & $554 \pm 99$ & $30.5 \pm 7.4$ & $187 \pm 9$ & $\mathrm{ND}^{\mathrm{a}}$ & $1137 \pm 155$ \\
\hline $4^{\text {th }}$ leaf pair & $624 \pm 68$ & $33.4 \pm 4.9$ & $215 \pm 14$ & $\mathrm{ND}^{\mathrm{a}}$ & $1109 \pm 260$ \\
\hline $5^{\text {th }}$ leaf pair & $654 \pm 96$ & $33.5 \pm 6.5$ & $204 \pm 27$ & $\mathrm{ND}^{\mathrm{a}}$ & $739 \pm 77$ \\
\hline
\end{tabular}

${ }^{\text {a }} \mathrm{ND}$ not detected

and especially pavettamine. Severe mortality in livestock occurs normally during NovemberDecember (spring to early summer); the time when gousiekte-causing plants sprout new growth (Hurter et al., 1972). This seems to be consistent with our finding that young leaves contain the highest concentration of pavettamine. This general relationship is unclear for putrescine and even the opposite for cadaverine, i.e. the oldest leaf pair contains the most cadaverine. 
Plant poisoning of livestock is responsible for considerable economic losses in southern Africa. Gousiekte is regarded as one of the six most important plant toxicoses in South Africa (Botha and Penrith, 2008; Hurter et al., 1972). Progression in the study of gousiekte was hampered by the lack of premonitory signs displayed by affected animals, individual susceptibility of the animals to the plant toxin and the long latent period (5-8 weeks). Another concern is the great variation in the toxicity of the different plant species (Fourie et al., 1995; Kellerman et al., 2005). It is known that the toxicity of at least some of the gousiekte plants varies depending on the period in the year, as well as from year to year. Furthermore, toxicity apparently also varies according to locality, habitat and climatic conditions (Fourie et al., 1995; Kellerman et al., 2005; Theiler et al., 1923). All of these contradictions and inconsistencies make the interpretation of findings reported in the literature rather difficult. No method has yet been described to analyze pavettamine concentrations. With the development of the sensitive new method for the detection and quantification of pavettamine described here, some of these problems can now be addressed. It is for instance now possible to obtain an accurate estimation of the pavettamine content of plants or to analyze fluctuations in the toxicity of the plants throughout the different seasons. Moreover this method provides the means to determine which developmental, climatologic or environmental factors have an impact on the amount of pavettamine produced by the plants.

\section{Most pavettamine was found to be conjugated in Fadogia homblei}

Considering the conjugated pool of polyamines, the most abundant polyamine was the gousiekte causing pavettamine. Roughly ten percent of the total pavettamine (free + conjugated) is in its free form. This percentage is similar for the different leaf pairs tested 
(from first to fifth: $12 \%, 11 \%, 8 \%, 12 \%$ and $10 \%$ ). The role that this conjugated pavettamine plays in the development of gousiekte is yet unknown. Although it is very plausible that it acts as a source of the toxin and that during digestion in the stomach of the ruminant, pavettamine is freed from its conjugates. To which molecules the pavettamine is conjugated remains unknown. One of the possibilities is that they are bound to phenolic compounds. In this respect it is noteworthy to refer to the pavettamine isolation paper of Fourie et al. (1995), where the extract was dialysed and the retentate ("interfering black, tarry, phenolic compounds") was discarded. The yield of pavettamine from Pavetta harborii was low, however, only the amount of free pavettamine was considered (Fourie et al., 1995). Our results show that conjugates of the other investigated polyamines were detected in decreasing order of magnitude for putrescine, spermidine and cadaverine. No conjugates were found for agmatine and spermine. After hydrolysis, a small increase (between 2.5 and $1.6 \mathrm{nmol} / \mathrm{mg}$ dry wt) in the amount of diaminopropane was observed.

The extraction procedure described by Fourie et al. (1995) could be used to assay plants for the presence of pavettamine. Yet, this method doesn't actually quantify pavettamine and, as the authors stated, it is tedious and the yield of the toxin is low. The use of mass spectrometry and the low detection limit for pavettamine $(0.3 \mathrm{pmol}$ in $6 \mu 1$ injected volume $)$ means that with the method described here, only few milligrams of plant sample material can be assayed in a very quick and sensitive way. It might be worth recalling that past efforts to prove the link between gousiekte and suspected plants encountered extensive difficulties. A significant amount of the initial feeding experiments gave negative results (Van Wyk et al., 1990). A previous experiment conducted at the Onderstepoort Veterinary Institute in which sheep were fed 
limited quantities of Fadogia homblei, gave negative results. It was hypothesized that the dose employed at that time was too low (Hurter et al., 1972). Therefore it was suggested that any rubiaceous plant could only be discounted as a possible causative agent of gousiekte, if subjected to extensive feeding experiments (Van Wyk et al., 1990). South Africa's flora harbors many plants closely related to the six known gousiekte-inducing species. It would be helpful to determine if in any of these plants the toxic principle is present and in which order of magnitude. It is quite possible that other Rubiaceae or even species from other plant families contain pavettamine, maybe in a lower dose, insufficient to cause gousiekte.

The endosymbiont of Fadogia homblei revealed no in vitro production of pavettamine In all six plant species that are known to cause gousiekte, bacterial endophytes were discovered in their leaves. Recent phylogenetic analysis of these bacteria revealed that they are all members of the Burkholderia genus, a group of highly diverse and environmentally adaptable plant-associated bacteria (Compant et al., 2008). The endophytes of both Pavetta species are confined to leaf nodules and proven to be different species (Lemaire et al., 2011; Verstraete et al., 2011). The non-nodulating Burkholderia of the Fadogia and Vangueria species are almost identical to Burkholderia caledonica LMG19076 ${ }^{\mathrm{T}}$ (Verstraete et al., 2011). It was therefore hypothesized that the toxin could be of bacterial origin, or is formed by either or both of the two associates as a result of the physiological interaction between plant and bacterium. Based on light and electron microscopic studies, Van Wyk et al. (1990) reported considerable variation in the amount of bacteria present in different plants of the same species and suggested that the variation in plant toxicity could reflect fluctuations in the bacterial population of the plants and/or virulence of various bacterial strains. The polyamine levels in different media 
constitutions of four different isolates of the endosymbiont of Fadogia homblei were analyzed. Under none of these conditions, pavettamine was detected. In bacterial isolates growing in MMAB medium (which contain malate as the only carbon source) for $12 \mathrm{~h}$ (exponential phase), putrescine (concentration of $\left.1561-1406 \mathrm{nmol} / 10^{9} \mathrm{CFU}\right)$, cadaverine $\left(3.1-2.3 \mathrm{nmol} / 10^{9}\right.$ $\mathrm{CFU})$ and spermidine $\left(0.65-0.39 \mathrm{nmol} / 10^{9} \mathrm{CFU}\right)$ were detected. Spermine, agmatine and diaminopropane were also detected with concentrations $<0.1 \mathrm{nmol} / 10^{9} \mathrm{CFU}$. In older cultures (24h, $48 \mathrm{~h}$ and $72 \mathrm{~h}$ ), the amount of putrescine was found to be lower, while cadaverine was raised slightly in $72 \mathrm{~h}$ cultures (data not shown). Addition of two important precursors in the biosynthesis of polyamines (arginine and lysine) in the culture medium, increased the production of several investigated polyamines, but could not induce the formation of pavettamine. In rich medium (LB medium), the isolates produced putrescine (concentrations between $\left.1063-543 \mathrm{nmol} / 10^{9} \mathrm{CFU}\right)$ and spermidine $\left(96.1-72.5 \mathrm{nmol} / 10^{9} \mathrm{CFU}\right)$ as the most abundant polyamines followed by spermine $\left(24.3-19.2 \mathrm{nmol} / 10^{9} \mathrm{CFU}\right)$, cadaverine $(7.9-5.0$ nmol/1 $\left.10^{9} \mathrm{CFU}\right)$, agmatine $\left(0.70-0.47 \mathrm{nmol} / 10^{9} \mathrm{CFU}\right)$ and diaminopropane $(0.45-0.37$ $\left.\mathrm{nmol} / 10^{9} \mathrm{CFU}\right)$. In low $\mathrm{pH}$ medium and in the iron-limiting medium, no pavettamine was detected. For both conditions, induction of the production of polyamines in certain bacteria has been reported (Shah and Swiatlo, 2008; Bergeron and Weimar, 1991). Our results provide evidence that the endosymbiont isolates of Fadogia homblei are not capable of producing pavettamine under the investigated culture conditions in vitro, since our method could detect pavettamine at minimal concentration. Although the endophytes could not synthesize pavettamine in culture medium, the possibility that both partners in this plant-bacteria interaction are needed for the synthesis of the toxin or that unknown signals induce the synthesis of pavettamine in the bacteria cannot be ruled out. This mode of action was, for 
example, already reported in the root nodule symbiosis of adzuki bean plants (Vigna angularis) and the bacterium Bradyrhizobium japonicum. A novel polyamine, 4-aminobutylcadaverine, was produced by the bacterium, only when ample cadaverine was provided by the plant. The bacterial strain itself failed to produce cadaverine. In the root nodule, where the host plant provides a cadaverine-rich environment, 4-aminobutylcadaverine could be detected (Fujihara et al., 1995). One approach towards resolving the origin of pavettamine would be to create bacteria-free plants (so-called "cripples"). In the case of nodulated Rubiaceae, these bacterial endosymbionts are necessary for the normal development of the host plant (Gordon, 1963; Van Oevelen et al., 2003). We are unaware of any experiments carried out that would suggest that this is also the case for the non-nodulated bacteriophilous Rubiaceae. Since the non-nodulating endophytes were successfully isolated, in contrast to the nodulating species, the symbiosis is not obligate on the bacterial side. However, in their work revealing the presence of endophytes in the leaves of Vangueria and Fadogia species, Van Wyk et al. (1990) suggested some kind of close symbiotic association since the presence of the endosymbionts was found to be consistent. There is also evidence that the endosymbionts of Fadogia are transferred to the next generation through the seeds (Verstraete et al., 2011), like in the case of the nodulated Psychotria (Lersten and Horner, 1967) and Pavetta (Von Teichman et al., 1981). By transferring nodulated plants of Psychotria to suboptimal conditions (increased temperature and decreased humidity) (Van Oevelen et al., 2003), or treatment of the seeds of Psychotria at $40^{\circ} \mathrm{C}$ for $48 \mathrm{~h}$ (Becking, 1971), crippled plants which are devoid of bacteria can be generated. However, in Pavetta provisional attempts to eliminate the endophyte by subjecting the seeds to a heat treatment were unsuccessful (Groenewald and Grobbelaar, 1978). Similar experiments 
should be carried out with Fadogia homblei plants or perhaps the other gousiekte causing plants, so that bacteria-free plants can be analyzed for their pavettamine content.

\section{A new method to analyze pavettamine and other polyamines}

We have developed the first method to quantify pavettamine, the toxic agent causing gousiekte, along with several other important polyamines (Dap, Put, Cad, Spd, Spm and Agm) in biological samples by means of tandem mass spectrometry following a chromatographic separation by UPLC ${ }^{\mathrm{TM}}$. Several techniques have been employed to analyze amines in plant tissues (reviewed in Boucherau et al. 2000). Applications of HPLC to plant amine analysis have traditionally been based on Reverse Phase-HPLC and pre-column dansyl or benzoyl derivatization with fluorescence or UV-detection. Because polyamines have a high $\mathrm{pKa}$, they are positively charged in a wide $\mathrm{pH}$ range, causing poor retention on reverse phase columns. Unprotonated amines $\left(\mathrm{NH}_{2}\right)$ react with carbonic or sulfonic acid chlorides at alkaline $\mathrm{pH}$ to form amide derivatives (Slocum et al., 1989). These derivatized polyamines have good retention on reverse phase columns. However, fluorescent and UV monitoring obliges to fully resolve signal peaks since interfering compounds or derivatization side-products could be superimposed over the signal peaks of the polyamines. Mass spectrometry is widely recognized as a very reliable detection and characterization system and when, coupled with GC or HPLC separation, is probably the most powerful approach of analyte monitoring available (Boucherau et al., 2000). Although it is generally not necessary to fully resolve signal peaks when using mass spectrometry, a good separation will facilitate detection because of higher machine dwell time and higher signal-to-noise ratio's. Another advantage is that derivatization increases the mass of the polyamines, which is normally rather low. This circumvents the interference of the 
many compounds that are present in this low mass range (Ducros et al., 2009). Because polyamines are extracted in polar solvents (5\% perchloric acid), derivatization and extraction in organic solvent (diethyl ether) itself is a purification step.

Table 3: MS/MS conditions for the detection of the studied polyamines and intra- and interday variation of polyamines in standard samples.

\begin{tabular}{|l|l|l|l|l|l|l|}
\hline Compound & $\begin{array}{l}\text { Ion transition } \\
(\mathrm{m} / \mathrm{z})\end{array}$ & $\begin{array}{l}\text { Benzoyl } \\
\text { groups }\end{array}$ & $\begin{array}{l}\text { Cone } \\
\text { voltage } \\
(\mathrm{V})\end{array}$ & $\begin{array}{l}\text { Collision } \\
\text { energy } \\
(\mathrm{eV})\end{array}$ & $\begin{array}{l}\text { Intraday } \\
\text { variation }^{\mathrm{a}} \\
(\% \mathrm{RSD})\end{array}$ & $\begin{array}{l}\text { Interday } \\
\text { variation }^{\mathrm{a}} \\
(\% \mathrm{RSD})\end{array}$ \\
\hline Dap & $283>162$ & 2 & 30 & 18 & 3.7 & 4.8 \\
\hline Put & $297>176$ & 2 & 30 & 18 & 2.5 & 3.0 \\
\hline Cad & $311>190$ & 2 & 30 & 18 & 1.7 & 1.6 \\
\hline Spd & $458>336$ & 3 & 40 & 18 & 4.7 & 6.6 \\
\hline DaH & $339>218$ & 2 & 30 & 18 & - & - \\
\hline Spm & $619>497$ & 4 & 40 & 25 & 7.6 & 12.2 \\
\hline Agm & $443>218$ & 3 & 40 & 25 & 5.4 & 8.2 \\
\hline Pav & $981>859$ & 7 & 40 & 25 & 4.2 & 10.0 \\
\hline
\end{tabular}

a expressed by their coefficient of variation

Each of the investigated benzoylated polyamines produced a much stronger signal in positive ionization mode than in negative mode. Therefore in all our analysis the electrospray ionization mode was set on positive. The appropriate MRM transition for each compound was determined 
by MS scans of the benzoylated standards to identify the precursor ion. Afterwards product ion scans of the selected precursor ion were run across a range of collision energy settings to identify the optimal product ion. The MS/MS conditions are summarized in Table 3. The [M $+\mathrm{H}]^{+}$ions were used in the MS/MS analysis. The diagnostic transition of derivatised pavettamine is derived from the loss of benzoic acid (see Fig.2). Benzoylated polyamines were separated on a C18 column using a 10 min gradient (see also Experimental). Retention times for all compounds are shown in Fig.3. Because the diagnostic transitions of Dap and Put are different (see Table 3), there is no need to fully resolving these signals, which would otherwise lead to broadening of the subsequent polyamine signal peaks. A dose-response curve for each polyamine was determined. Benzoylated polyamines were found linear in the range 10 $\mathrm{nmol} / \mathrm{ml}$ to $0.05 \mathrm{nmol} / \mathrm{ml}$ for Dap, Put, Cad, Spd, Dah; $8 \mathrm{nmol} / \mathrm{ml}$ to $0.05 \mathrm{nmol} / \mathrm{ml}$ for Pav and $6 \mathrm{nmol} / \mathrm{ml}$ to $0.05 \mathrm{nmol} / \mathrm{ml}$ for $\mathrm{Spm}$ and Agm. The slope of each dose-response curve was linear with a regression coefficient of at least 0.99 . Intra- and interday variation in the assay was evaluated at the concentration level of $5 \mathrm{nmol} / \mathrm{ml}$ by analyzing five replicates on the same day (intraday) and on five different days (interday) (see Table 3). Both intra- and interday variation of all tested compounds are below $15 \%$, which proves that the procedure is repeatable. Polyamines were quantified by dividing the peak area of the target polyamine with the peak area of the IS multiplied with the amount of IS added. This value was adjusted with the response factor found by comparing the slope of the dose-response curve from the internal standard to the slope of the dose response curve of the target polyamine. Acid conjugated polyamine concentrations were calculated by subtracting the value of free polyamines by the value found in extracts after hydrolysis. 
A

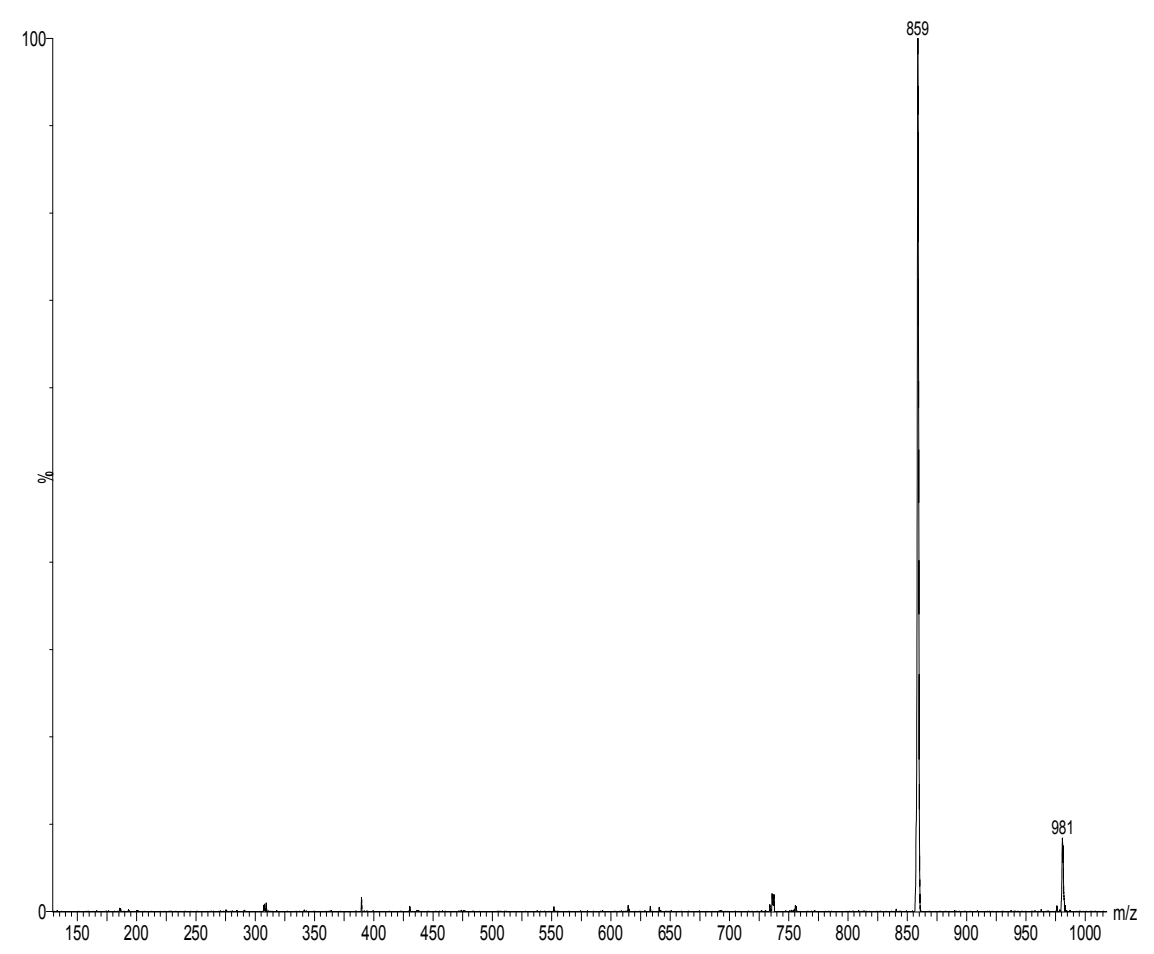

B
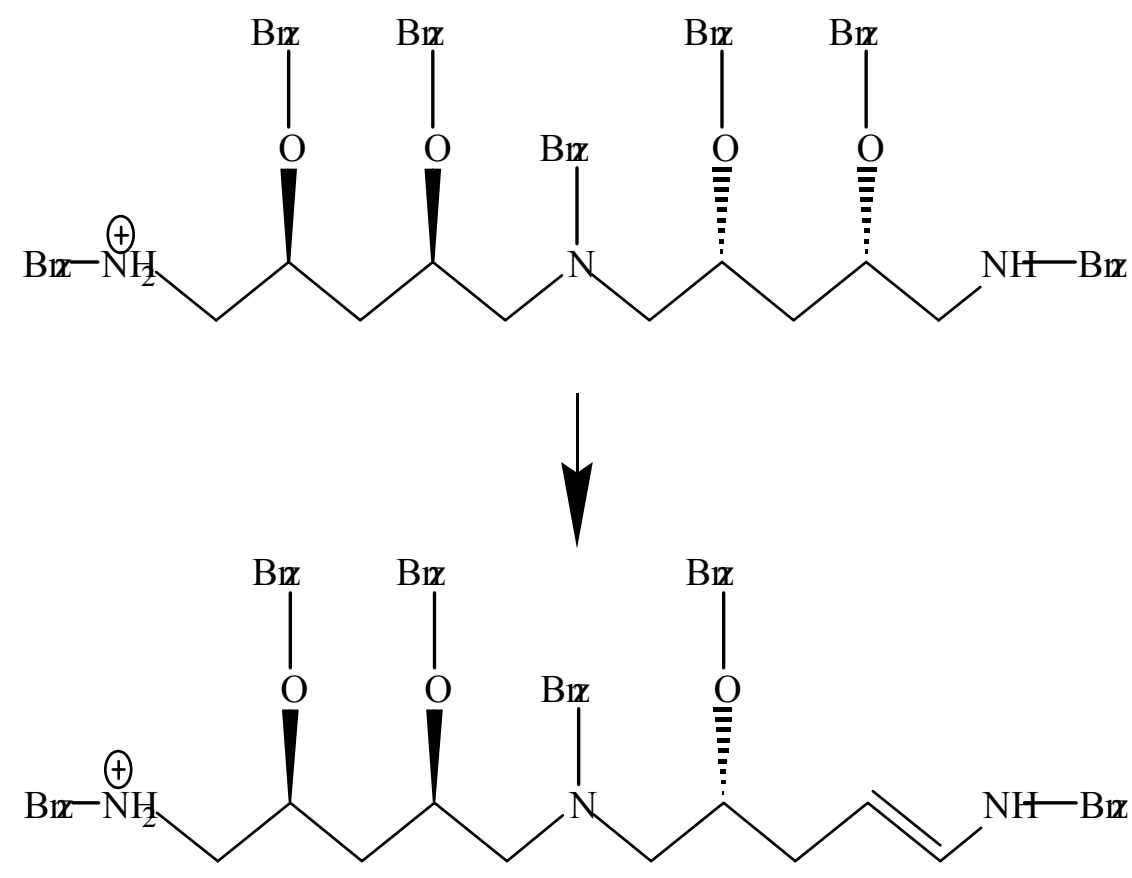

Fig. 2. A, Spectrum of $\mathrm{m} / \mathrm{z} 981$, the benzoylated pavettamine parent ion, showing the product ions 859 (loss of benzoic acid), minor product ions $\mathrm{m} / \mathrm{z} 308$ and $\mathrm{m} / \mathrm{z}$ 737. B, Mechanism for the formation of the $\mathrm{m} / \mathrm{z} 859$ product ion. 

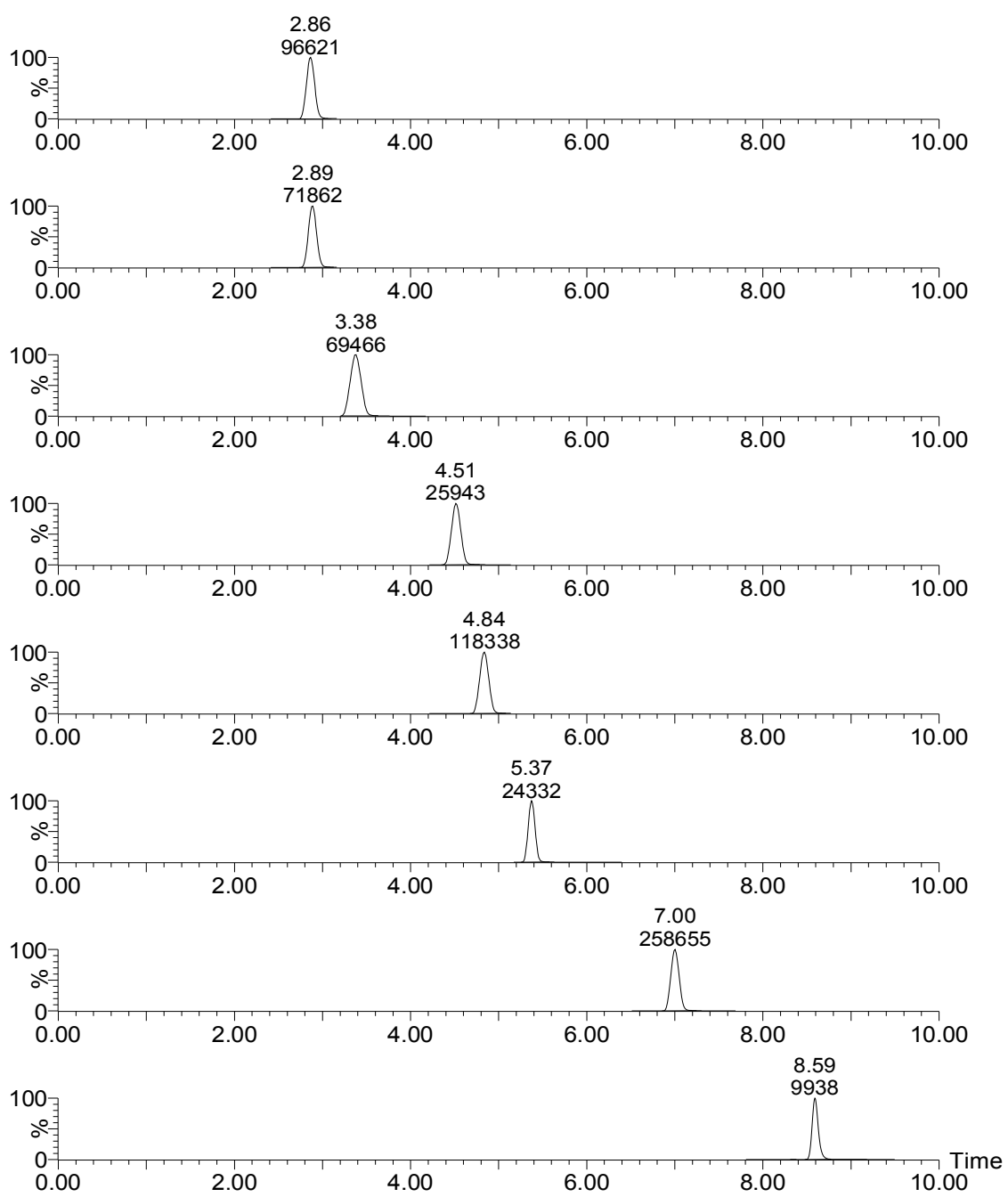

Fig. 3. Chromatogram of benzoyl derivatives of the investigated polyamines from a $6 \mathrm{nmol} / \mathrm{ml}$ solution, showing retention time and area. From top to bottom: Dap, Put, Cad, Spd, Dah, Spm, Agm and Pav. 


\section{Concluding remarks}

The diagnosis of plant poisonings in livestock is not always simple and depends on a good case history and an evaluation of clinical signs and pathological lesions, as well as on confirmatory laboratory tests (where they exist) (Botha and Penrith, 2008). Although gousiekte was reported to be the most common cause of cardiomyopathy in southern Africa, the myocardial lesions are not pathognomonic. Diagnosis of gousiekte was justified in cases of cardiomyopathy when one of the plants known to cause the condition is present (Lawrence et al., 2010; Prozesky, 2008). However, little is known about the early start of the disease. Because of the lack of overt premonitory signs during the latent period of gousiekte, it is usually impossible to identify affected animals, even shortly before death (Fourie et al., 1989). With the sensitive method for the detection of pavettamine reported here, it would be possible to analyze the pavettamine concentration in the blood of animals or in tissue collected post mortem. Such tests could strengthen the diagnosis of gousiekte, or identify affected animals in an early stage of the disease. No treatment has yet been described to cure gousiekte, but the finding of Prozesky (2008) suggests that animals can recover if exposed to a non-lethal dose of pavettamine. Animals that tested positive for pavettamine in their blood can then be placed on an alternative diet and confined to pens to prevent additional pavettamine intake and agitation, since exercise is known to provoke death. From these applications, it becomes clear that the method to detect pavettamine presented here, could clarify the role of plant and bacteria in causing gousiekte and that it provide solid means to study the effect of environmental conditions on the plants toxicity and a perspective for diagnostic analysis of gousiekte in cattle. 


\section{Experimental}

\section{Chemicals}

Polyamine standards: 1,3-diaminopropane (Dap), 1,4-diaminobutane (putrescine, Put), 1,5diaminopentane (cadaverine, Cad), N-(3-aminopropyl)-1,4-diaminobutane (spermidine, Spd), N,N'-Bis(3-aminopropyl)-1,4-diaminobutane (spermine, Spm), 1-amino-4-guanidinobutane (agmatine, Agm) and the internal standard 1,7-diaminoheptane (Dah) were obtained from Sigma Aldrich (Schnelldorf, Germany). A pavettamine standard was obtained from the Onderstepoort Veterinary Institute (OVI) (Onderstepoort, South Africa). Acetonitrile (HPLC grade), water (HPLC grade) and ether were from VWR prolabo (Leuven, Belgium). Benzoyl chloride was of reagent grade, $>99 \%$ purity A.C.S. (Sigma Aldrich).

\section{Sample material and bacterial growth conditions}

Material of Fadogia homblei plants was collected during a field expedition to South Africa in February 2010. The collection site was the Woodlands Game Lodge (253 $30^{\prime} 51.83^{\prime \prime} \mathrm{S} \quad 28^{\circ} 26^{\prime}$ 49.58" E). Herbarium vouchers are deposited at BR or PRE. The distal first five leaf pairs from the growth point on actively growing shoots were removed and each pair was immediately and individually frozen in liquid nitrogen. Leaf samples were subsequently freeze dried.

Bacterial endosymbionts of Fadogia homblei, previously isolated and identified as a Burkholderia species provisionally considered conspecific with B. caledonica (Verstraete et al., (2011), were analyzed for their capabilities to produce pavettamine in different culture media. Bacteria were grown in LB medium for 24h, 48h, 72h; LB medium buffered at pH 7.6 with a final concentration of $100 \mathrm{mM} 3-(N$-morpholino)propanesulfonic acid (MOPS) and LB 
medium buffered at pH 5.8 with a final concentration of $100 \mathrm{mM} 2-(\mathrm{N}-$ morpholino)ethanesulfonic acid (MES) for 24h (Watson et al., 1992), MMAB medium (Vanstockem et al., 1987) for 12h, 24h, 48h, 72h, MMAB medium supplemented with 100 $\mathrm{mg} / 1 \mathrm{~L}-\mathrm{Lysine}$ or L-Arginine for $24 \mathrm{~h}$ and in iron restricted medium that consisted of MMAB medium without $\mathrm{FeSO}_{4}$ and supplemented with $200 \mu \mathrm{M}$ 2,2-Dipyridyl (DPD).

\section{Extraction and derivatization of free and conjugated polyamines}

The derivatization procedure was based on the method described by Flores and Galston (1982), which has been widely adopted for polyamine studies in plants. Leaf samples were grounded in liquid nitrogen using mortar and pestle and subsequently freeze dried. Polyamines were extracted by adding $2 \mathrm{ml}$ perchloric acid (5\%) per $100 \mathrm{mg}$ of powdered tissue. After incubation on ice for $30 \mathrm{~min}$, the homogenate was centrifuged $\left(20 \mathrm{~min}, 20000 \mathrm{~g}, 4^{\circ} \mathrm{C}\right) .250 \mu 1$ of this extract was mixed with $1.5 \mathrm{ml} 2 \mathrm{~N} \mathrm{NaOH}$ and 200 pmol IS. Plant extracts were derivatized using $20 \mu \mathrm{l}$ benzoyl chloride ( $20 \mathrm{~min}$., room temperature). Benzoylated polyamines were extracted in $4 \mathrm{ml}$ diethyl ether. The aquous phase was discarded; the ether phase was washed with twice distilled water, collected and evaporated under a stream of nitrogen. Samples were stored at $-20^{\circ} \mathrm{C}$ until being redissolved in $80 \% \mathrm{ACN}$ and transferred to inserts before injection in a UPLC ${ }^{\mathrm{TM}} \mathrm{MS} / \mathrm{MS}$ system. The amount of polyamine conjugates was measured indirectly by the release of free polyamines using acid hydrolysis. Briefly, aliquots of the perchloric acid extracts were dried in glass tubes using a SpeedVac (RVC-25, Christ Freeze Dryers, Osterode, Germany), and subsequently placed in a vacuum container in the presence of a minimal volume $(250 \mu \mathrm{l})$ of $6 \mathrm{M} \mathrm{HCl}$ and heated for 2 hours at $100^{\circ} \mathrm{C}$ (Chauvaux, 1997). Freed 
polyamines were analyzed using the derivatization procedure above. Polyamines from plants are expressed in $\mathrm{nmol} / \mathrm{g}$ dry weight.

Analysis of bacterial polyamines was carried out by collecting $10 \mathrm{ml}$ culture medium that was subsequently freeze-dried, redissolved in $2 \mathrm{~N} \mathrm{NaOH}$ and sonicated to shear bacterial cells. Polyamines were derivatized using $30 \mu \mathrm{l}$ benzoyl chloride and extracted in ether. The absorbance of the culture was determined at $600 \mathrm{~nm}$ with a plate reader (Labsystems Multiscan $\mathrm{RC}$, Zellik, Belgium). The ratio between the $\mathrm{A}_{600}$ and the number of colony forming units per millilitre $\left(\mathrm{CFU} \mathrm{m} \mathrm{m}^{-1}\right)$ of each bacterial culture was experimentally determined by plating serial dilutions and counting the number of colonies that were formed (Dalgaard et al., 1994). Bacterial polyamines are expressed in $\mathrm{pmol} /\left(10^{9} \mathrm{CFU}\right)$.

\section{Analysis of benzoylated polyamines by UPLC-MS/MS}

Chromatography and detection by mass spectrometry was performed using an ACQUITY UPLC $^{\mathrm{TM}}$ TQD system (Waters, Micromass, Ltd., Manchester, United Kingdom) equipped with electrospray ionization. $6 \mu \mathrm{l}$ (partial loop) of the redissolved sample was injected in an ACQUITY UPLC ${ }^{\mathrm{TM}}$ BEH C18 column $(1.7 \mu \mathrm{m}$ x $2.1 \mathrm{~mm}$ x $50 \mathrm{~mm}$, Waters $)$ fitted with a VanGuard $^{\mathrm{TM}}$ Pre-Column $(2.1 \mathrm{~mm}$ x $5 \mathrm{~mm}$, Waters). The mobile phase for elution was a gradient constituted of water containing $0.1 \%$ formic acid (solvent $\mathrm{A}$ ) and acetonitrile containing $0.1 \%$ formic acid (solvent B). The UPLC gradient profile was as follows: initial $90 \%$ A, after $0.5 \min 80 \%$ A, $4.0 \min 65 \%$ A, $5.7 \min 47 \%$ A, $5.9 \min 42 \%$ A, $8.3 \min 35 \%$ A, $8.5 \min 100 \% \mathrm{~B}$ and $9.0 \min 90 \% \mathrm{~A}$. The total UPLC run time was 10 minutes, the solvent flow rate was $0.4 \mathrm{ml} \mathrm{min}^{-1}$. The effluent was introduced into the electrospray source at a source 
temperature of $120^{\circ} \mathrm{C}$, the capillary voltage was set at $0.84 \mathrm{kV}$ and the collision gas was argon with a collision flow of $0.2 \mathrm{ml} / \mathrm{min}$. The mass spectrometer was used in multiple reactionmonitoring mode (MRM). Optimal conditions for the detection of benzoylated polyamines were obtained by injecting standards to determine cone, collision energies, precursor and product ions. Masslynx NT version 4.1 (Waters) software was used to analyze the data.

\section{Acknowledgments}

The authors would like to thank Tim Willems for technical assistance, Elsa Van Wyk for providing literature and Kris Vissenberg for critical reading of the manuscript and helpful suggestions. This research was supported financially by the Fund for Scientific Research, Flanders (F.W.O., G.0343.09N). D.V.E. holds a Ph.D. research grant from the Fund for Scientific Research, Flanders (F.W.O., no. 1.1.722.10.N.00). The funders had no role in study design, data collection and analysis, decision to publish, or preparation of the manuscript.

\section{Reference list}

Bassard, J-E., Ullmann, P., Bernier, F., Werck-Reichhart, D., 2010. Phenolamides: Bridging polyamines to the phenolic metabolism. Phytochemistry 71, 1808-1824.

Becking, J.H., 1971. The physiological significance of the leaf nodules of Psychotria. Plant and Soil, Special Volume, 361-374. 
Bergeron, R.J., Weimar, W.R., 1991. Increase in spermine content coordinated with siderophore production in Paracoccus denitrificans. J. Bacteriol. 173, 2238-2243.

Bode, M.L., Gates, P.J., Gebretnsae, S.Y., Vleggaar, R., 2010. Structure elucidation and stereoselective total synthesis of pavettamine, the causal agent of gousiekte. Tetrahedron 66, 2026-2036.

Botha, C.J., Penrith, M.L., 2008. Poisonous plants of veterinary and human importance in southern Africa. J. Ethnopharm. 119, 549-558.

Boucherau, A., Guénot, P., Larher, F., 2000. Analysis of amines in plant materials. J. Chromatogr. B 747, 49-67.

Chauvaux, N., Van Dongen, W., Esmans, E.L., Van Onckelen, H.A., 1997. Quantitative analysis of 1-aminocyclopropane-1-carboxylic acid by liquid chromatography coupled to electrospray tandem mass spectrometry. J. Chromatogr. A 775, 143-150.

Compant, S., Nowak, J., Coenye, T., Clement, C., Ait Barka, E., 2008. Diversity and occurrence of Burkholderia spp. in their natural environment. FEMS Microbiol. Rev. 32, 607626. 
Dalgaard, P., Ross, T., Kamperman, L., Neumeyer, K., McMeekin, T.A., 1994. Estimation of bacterial growth rates from turbidimetric and viable count data. Int. J. Food Microbiol. 23, 391404.

Ducros, V., Ruffieux, D., Belva-Besnet, H., de Fraipont, F., Berger, F., Favier, A., 2009. Determination of dansylated polyamines in red blood cells by liquid chromatography-tandem mass spectrometry. Anal. Biochem. 390, 46-51.

Flores, H.E., Galston, A.W., 1982. Analysis of polyamines in higher plants by high performance liquid chromatography. Plant Physiol. 69, 701-706.

Fourie, N., Schultz, A.R., Prozesky, L., Kellerman, T.S., Labuschagne, L., 1989. Clinical pathological changes in gousiekte, a plant-induced cardiotoxicosis of ruminants. Onderstepoort J. Vet. Res. 56, 73-80.

Fourie, N., Erasmus, G.L., Schultz, R.A., Prozesky, L., 1995. Isolation of the toxin responsible for gousiekte, a plant-induced cardiomyopathy of ruminants in southern Africa. Onderstepoort J. Vet. Res. 62, 77-87.

Fujihara, S., Abe, H., Yoneyama, T., 1995. A new polyamine 4-Aminobutylcadaverine. J. Biol. Chem. 270, 9932-9938. 
Galston, A.W., Sahwney, R.K., 1990. Polyamines in plant physiology. Plant Physiol. 94, 406410.

Gordon, J.F., 1963. The nature and distribution within the plant of the bacteria associated with certain leaf-nodulated species of the families Myrsinaceae and Rubiaceae. PhD Thesis. University of London, Imperial College.

Groenewald, E.G., Grobbelaar, N., 1978. Extractable and diffusible gibberellin-like substances in normal and dwarf Pavetta assimilis Sond. seedlings. S. Afr. J. Sci. 74, 483-485.

Hurter, L.R., Naudé, T.W., Adelaar, T.F., Smit, J.D., Codd, L.E., 1972. Ingestion of the plant Fadogia monticola Robyns as an additional cause of gousiekte in ruminants. Onderstepoort J. Vet. Res. 39, 71-82.

Kellerman, T.S., Coetzer, J.A.W., Naudé, T.W., Botha, C.J., 2005. Plant poisonings and mycotoxicoses of livestock in southern Africa, second ed. Oxford University Press, Cape Town.

Kusano, T., Berberich, T., Tateda, C., Takahashi, Y., 2008. Polyamines: essential factors for growth and survival. Planta 228, 367-381.

Lawrence, J.A., Foggin, C.M., Prozesky, L., 2010. Gousiekte in African buffalo (Syncerus caffer). J. S. Afr. Vet. Assoc. 81, 170-171. 
Lemaire, B., Van Oevelen, S., De Block, P., Verstraete, B., Smets, E., Prinsen, E., Dessein, S., 2011. Identification of the bacterial endosymbionts in leaf nodules of Pavetta (Rubiaceae). Int. J. Syst. Sci. doi:ijs.0.028019-0.

Lersten, N.R., Horner, H.T., 1967. Development and structure of bacterial leaf nodules in Psychotria bacteriophila Val.(Rubiaceae). J. Bacteriol. 94, 2027-2036.

Pretorius, P.J., Terblanche, M., 1967. A preliminary study on the symptomatology and cardiodynamics of gousiekte in sheep and goats. J. S. Afr. Vet. Med. Assoc. 38, 29-52.

Prozesky, L., 2008. A study of the pathology and pathogenesis of myocardial lesions in gousiekte, a cardiotoxicosis of ruminants. $\mathrm{PhD}$ Thesis. University of Pretoria.

Schultz, R.A., Fourie, N., Basson, K.M., Labuschagne, L., Prozesky, L., 2001. Effect of pavetamine on protein synthesis in rat tissue. Onderstepoort J. Vet. Res. 68, 325-330.

Shah, P., Swiatlo, E., 2008. A multifaceted role for polyamines in bacterial pathogens. Mol. Microbiol. 68, 4-16.

Slocum, R.D., Flores, H.E., Galston, A.W., Weinstein, L.H., 1989. Improved method for HPLC analysis of polyamines, agmatine and aromatic monoamines in plant tissue. Plant Physiol. 89, 512-517. 
Theiler, A., Du Toit, P.J., Mitchell, D.T., 1923. Gousiekte in sheep. In: $9^{\text {th }}$ and $10^{\text {th }}$ reports of the director of veterinary education and research, Onderstepoort, Pretoria. The Government Printing and Stationary Office.

Van Oevelen, S., De Wachter, R., Robbrecht, E., Prinsen, E., 2003. Induction of a crippled phenotype in Psychotria (Rubiaceae) upon loss of the bacterial endophyte. Bulg. J. Plant Physiol. Special Issue, 242-247.

Vanstockem, M., Michiels, K., Vanderleyden, J., Van Gool, A., 1987. Transposon mutagenesis of Azospirillum brasilense and Azospirillum lipoferum: physical analysis of Tn5 and Tn5-Mob insertion mutants. Appl. Environ. Microbiol. 53, 410-415.

Van Wyk, A.E., Kok, P.D.F., Van Bers, N.L., Van der Merwe, C.F., 1990. Non-pathological bacterial symbiosis in Pachystigma and Fadogia (Rubiaceae): its evolutionary significance and possible involvement in the aetiology of gousiekte in domestic ruminants. S. Afr. J. Sci. 86, 9396.

Verstraete, B., Van Elst, D., Steyn, H., Van Wyk, B., Lemaire, B., Smets, E., Dessein, S., 2011. Endophytic bacteria in toxic South African plants: identification, phylogeny and possible involvement in gousiekte. PLoS ONE 6(4):e19265.doi10.1371/journal.pone.0019265 
Von Teichman, I., Robbertse, P.J., Van der Merwe, C.F., 1981. Contributions to the floral morphology and embryology of Pavetta gardeniifolia A.Rich. Part 2. The ovule and megasporogenesis. S. Afr. J. Bot.1, 22-27.

Walters, D.R., 2003. Polyamines and plant disease. Phytochemistry 64, 97-107.

Watson, N., Dunyak, D.S., Rosey, E.L., Slonczewski, J.L., Olson, E.R., 1992. Identification of elements involved in transcriptional regulation of the Escherichia coli cad operon by external pH. J. Bacteriol. 174, 530-540.

Wortham, B.W., Patel, C.N., Oliveira, M.A., 2007. Polyamines in bacteria: pleiotropic effects yet specific mechanisms. Adv. Exp. Med. Biol. 603, 106-115. 